\title{
Evaluation of Conjugated Linoleic Acid (CLA) Supplementation on Equine Body Composition
}

\author{
Miller EF ${ }^{1}$, Leatherwood JL ${ }^{2 *}$, Anderson $\mathbf{M J}^{1}$ and Beverly $\mathbf{M M}^{1}$ \\ ${ }^{1}$ Department of Animal Science, USA \\ ${ }^{2}$ Department of Agricultural Sciences and Engineering Technology, USA \\ *Corresponding author: Leatherwood JL, Department of Animal Science, College Station, USA
}

Submission: 海 March 31, 2018; Published: 眥 April 13, 2018

\begin{abstract}
Fatty acids, like omega-3s, are often supplemented to horses to increase the caloric density of a diet and to replace soluble carbohydrates. Palatability limitations of omega-3s have led to an interest in alternative sources like Conjugated Linoleic Acid (CLA) that exert health effects similar to omega-3s. However, the effect of CLA on equine body composition has not been established. The purpose of this investigation was to evaluate the effects of dietary CLA supplementation on equine body composition. Nine stock-type horses were stratified by age, body weight, and sex, and randomly assigned to one of two dietary treatments for a 12-wk study. Diets were formulated to be isocaloric and isonitrogenous and consisted of 0.015\% BW/d (AF) of CLA (n=5) or soybean oil ( $\mathrm{n}=4$; control) that was top-dressed and mixed immediately prior to feeding. Performance measurements were collected weekly; rump fat thickness, Ribeye area, and intramuscular fat were measured on days 0,42 , and 84 by a certified technician. The MIXED procedure in SAS was used with repeated measures to detect differences in measurements. There were no differences in performance characteristics or body fat content between treatment groups $(\mathrm{P}>0.05)$. To account for initial differences between treatments $(\mathrm{P}<0.05)$, ribeye area between the $17^{\text {th }}$ and $18^{\text {th }}$ ribs $(\mathrm{REA17})$ was analyzed with day 0 as a covariate. Mean REA17 tended $(\mathrm{P}<0.10)$ to be higher in CLA supplemented horses than controls. Results suggest that CLA does not affect equine body composition, but further study is necessary to elucidate potential benefits of CLA in the horse.
\end{abstract}

Key Words: Conjugated linoleic acid; Equine; Body composition

Abbreviations: Conjugated Linoleic Acid (CLA); Body Weight (BW); Body Condition Score (BCS); As-Fed (AF); Rump Fat Thickness (RFT); Ribeye Area (REA); Back Fat Thickness (BF); Intra Muscular Fat (IMF)

\section{Introduction}

Conjugated Linoleic Acid (CLA) refers to a group of positional and stereoisomers of conjugated Octadecadienoic acid (18:2), or Linoleic acid [1-4]. While CLA is made up of several isomers of linoleic acid, previous studies have shown that specific isomers are responsible for the different physiological effects attributed to CLA supplementation. For instance, it has been shown that the t10,c12CLA isomer is primarily responsible for the reduction of body fat gain, whereas both the $\mathrm{c} 9, \mathrm{t} 11$ - and $\mathrm{t} 10, \mathrm{c} 12$-CLA isomers appear to be effective in inhibiting carcinogenesis [3,5-8].

One potential benefit to the equine industry is the ability of CLA to reduce the accumulation of adipose tissue. Several studies have shown that supplementing CLA to the diet improves the carcass quality of finishing swine by increasing the rate and efficiency of gain, reducing fat deposition, and increasing lean tissue [1,9-11]. However, because there are considerable differences in the effect of CLA on different species, there is still much about the effects of CLA that is unknown, especially in equine model. Previous work with horses has reported that supplementing CLA to equine diets can alter circulating fatty acid levels, by decreasing plasma arachidonic acid concentrations as well as serum triglycerides and total cholesterol [2]. However, no changes in body condition or body weight were observed as a result of supplementation at a rate of $0.30 \%$ of the daily intake, potentially due to the low inclusion rate of CLA. Therefore, the objective of this study was to evaluate the effects of supplementing elevated levels of CLA on equine body composition.

\section{Materials and Methods}

\section{Horses and dietary treatments}

All experimental procedures were approved by the Sam Houston State University (SHSU) Institutional Animal Care and Use Committee (16-09-08-1008-3-01) prior to the start of the experiment. Nine stock-type mares and geldings (1-3 years, $382.91 \pm 12.87 \mathrm{~kg}$ ) were utilized in a completely randomized design for a 12-week study. Horses where stratified by age, Body Weight (BW), and sex, and randomly assigned to dietary treatments. Dietary treatments were formulated to be isocaloric and isonitrogenous, and consisted of either CLA (BASF Corp., Florham Park, NJ) or 
soybean oil control (CON; $n=5$ and 4/group, respectively) that was offered at $1.5 \%$ of the total daily concentrate diet (As-Fed, AF) and top-dressed and mixed with concentrate immediately prior to feeding. The CLA supplement contained 55\% CLA with a mixture of cis- 9 , trans- 11 and trans- 10 , cis 12 isomers.

Horses were fed at 1\% BW (AF) daily of a commercially available pelleted concentrate (Safe Choice, Cargill Animal Nutrition, Elk River, MN) and approximately 1\% BW of coastal Bermuda grass hay divided equally between two meals at 12 hour intervals. Body weight was obtained every 7 days with concentrate intake adjusted accordingly. Diets were formulated to meet or exceed all National Research Council (2007) nutritional requirements for growing horses performing light exercise. Horses were housed in $3 \times 3 \mathrm{~m}$ individual stalls for the duration of this study and were used in conjunction with the equine behavior and training course. All horses were randomly assigned to students in the class. Horses were exercised 5 days per week for a total of $30-40 \mathrm{~min}$ in accordance with course requirements. Type of activity, duration (minutes), along with direction was monitored daily in order to maintain consistent workloads across all horses throughout the trial. A daily log was kept in order to record exercise load and incidence of injury or lameness.

\section{Physical measurements}

Morphometric measurements including BW, Body Condition Score (BCS), heart girth, crest circumference, and crest score were obtained weekly. Heart girth circumference was measured by placing the soft tape measure caudal to the elbow (Olecranon Tuber) and $2.54 \mathrm{~cm}$ behind the slope of the withers. Crest circumference was obtained while the neck was held in a relaxed position by placing the soft tape measure around the neck measured halfway between the poll and the withers. Body condition and crest scores were determined weekly utilizing the scales outlined in Henneke et al. [12] and Carter et al. [13], respectively.

Rump Fat Thickness (RFT), Ribeye Area (REA), Back Fat Thickness (BF), and Intra Muscular Fat (IMF) measurements were conducted via transdermal ultra sonography by the same centralized ultrasound processing certified technician using an ultrasound system (Aloka SSD-500V, Aloka Inc., Tokyo, Japan) in conjunction with a $3.5 \mathrm{MHz} 172 \mathrm{~mm}$ linear transducer. Measurements were taken on days 0,42 , and 84 following the initiation of supplementation. A certified technician through centralized ultrasound processing, which was blinded to dietary treatment, analyzed all images.

A cross-sectional image between the $13^{\text {th }}$ and $14^{\text {th }}$ ribs (REA13 and BF13, respectively) and between the $17^{\text {th }}$ and $18^{\text {th }}$ ribs (REA17 and BF17, respectively) was obtained to determine REA and BF. Images were obtained $5 \mathrm{~cm}$ lateral from the midline halfway between the first coccygeal vertebrae and the ischium to determine RFT [14]. Measurements within the longissimus dorsi were obtained by imaging parallel to the backbone between the $17^{\text {th }}$ and $18^{\text {th }}$ ribs to determine IMF. To ensure proper contact between transducer and horse, the transducer was fitted with a PIA contour pad (Animal Ultrasound Services, Ithaca, NY) designed to conform to the curvature of a horse's back. In addition, corn oil was applied to promote acoustical contact between animal and transducer [15].

\section{Statistical analysis}

Changes in growth performance, morphometric measurements, and ultrasound measurements were analyzed using the MIXED procedure in SAS v. 9.4 (SAS Inst. Inc., Cary, NC). The model contained effects for treatment, time, and treatment $\mathrm{x}$ time interaction. Additionally, the GLM procedure in SAS was used to determine within day effects of treatments. If differences were detected at day 0 , a covariate was added to the model statement to account for initial differences between experimental units. Effects were considered significant when $\mathrm{P} \leq 0.05$ and a tendency declared when $\mathrm{P} \leq 0.10$.

\section{Results and Discussion}

\section{Performance Measurements}

Daily intake did not differ across dietary treatments ( $\mathrm{P}>0.05)$ Body composition measurements including BW, BCS, heart girth, crest score, and crest circumference for horses consuming either CLA or soybean oil did not differ across treatments (Table 1). Similarly, BW and BCS did not differ between treatments $(\mathrm{P}=0.17$ and 0.20 , respectively); however, all horses regardless of treatment, gained $(\mathrm{P}<0.01) \mathrm{BW}$ and $\mathrm{BCS}$ over the 12-week trial. As expected from the increase in BW and BCS, heart girth, crest circumference, and crest score also increased over time $(\mathrm{P}<0.01)$ but did not differ across treatments $(\mathrm{P}=0.55$ and 0.82 , respectively). There was, however, a tendency for heart girth to be higher in CLA supplemented horses over time $(\mathrm{P}=0.07)$. Results of this study indicate that CLA supplementation does not influence BW, BCS, or other growth performance measurements such as heart girth and crest circumference.

Table 1: Mean BW (kg), Body Condition Score (BCS), heart girth $(\mathrm{cm})$, crest score, and crest circumference $(\mathrm{cm})$ for horses consuming either CLA1 or soybean oil $(\mathrm{CON})$ that served as an isocaloric control. Diets were offered at $1.5 \%$ of the total daily concentrate on an as-fed basis, and top-dressed and mixed with concentrate immediately prior to feeding.

\begin{tabular}{|c|c|c|c|c|c|}
\hline Variable & $\begin{array}{c}\text { CON } \\
(\mathbf{n = 4 )}\end{array}$ & $\begin{array}{c}\text { CLA } \\
(\mathbf{n = 5})\end{array}$ & SEM2 & Treatment3 & Time4 \\
\hline BW (kg) & 385.74 & 424.82 & 12.87 & 0.17 & $<0.01$ \\
\hline BCS & 5.5 & 5.88 & 0.15 & 0.2 & $<0.01$ \\
\hline Heart Girth (cm) & 169.03 & 173.22 & 2.13 & 0.34 & $<0.01$ \\
\hline Crest Score & 1.73 & 2.03 & 0.3 & 0.61 & $<0.01$ \\
\hline $\begin{array}{c}\text { Crest } \\
\text { Circumference } \\
\text { (cm) }\end{array}$ & 87.07 & 90.78 & 1.73 & 0.25 & $<0.01$ \\
\hline
\end{tabular}

${ }^{1}$ Conjugated linoleic acid supplement manufactured by BASF Corp. (Florham Park, NJ).

${ }^{2}$ Pooled Standard error of the treatment mean.

${ }^{3}$ Treatments included at $0.015 \%$ BW daily.

${ }^{4}$ Measurements obtained weekly over the 84-day study. 
This coincides with results of Headley et al. [2], who did not find an effect of CLA on body condition scores (5.79 \pm 1.08 BCS) when compared to controls $(5.83 \pm 1.23 \mathrm{BCS}, \mathrm{P}=0.67)$. While previous literature has shown that CLA exhibits an anti-adipogenic effect on body composition in numerous species including swine, rats, and humans $[1,9,10]$, the same effect has not been successfully seen in the horse. The effect of CLA on body composition has been shown to be quite variable across species, so it is possible that CLA does not exert the same anti-adipogenic effect in equine as seen in other species.
Alternatively, the effect of CLA on body composition is dependent on pre-existing adiposity, and as such, may be more evident in obese or insulin-resistant horses than in young, developing horses. For instance, both Chin et al. [16] and Noto et al. [17] reported a significant improvement in lipid metabolism in insulin-resistant rats supplemented with CLA. In this study, there was a tendency for heart girth to be higher in CLA supplemented horses over time, therefore CLA may affect body composition. Future studies with prolonged CLA supplementation periods are needed to help clarify the effect of CLA on equine body composition.

\section{Ultrasound measurements}

Table 2: Mean REA17 $\left(\mathrm{cm}^{2}\right), \operatorname{BF} 17(\mathrm{~cm}), \operatorname{REA} 13\left(\mathrm{~cm}^{2}\right)$, BF13 $(\mathrm{cm}), \operatorname{IMF}(\%)$, and RFT (cm) on d 0 , 42 , and 84 for horses consuming either both CLA1 or soybean oil (CON) that served as an isocaloric control. Diets were offered at $1.5 \%$ of the total daily concentrate diet on an as-fed basis, and top-dressed and mixed with concentrate immediately prior to feeding.

\begin{tabular}{|c|c|c|c|c|c|c|c|c|c|c|c|c|}
\hline \multirow{2}{*}{$\begin{array}{c}\text { Day } \\
\text { Variable }\end{array}$} & \multicolumn{7}{|c|}{$\mathbf{0}$} & \multicolumn{3}{|c|}{$42^{2}$} & \multicolumn{2}{|c|}{$84^{2}$} \\
\hline & $\begin{array}{c}\text { CON } \\
(n=4)\end{array}$ & $\begin{array}{c}\text { CLA } \\
(n=5)\end{array}$ & SEM $^{3}$ & $\begin{array}{c}\text { P-Valu } \\
\mathrm{e}^{10}\end{array}$ & $\begin{array}{c}\text { CON } \\
(n=4)\end{array}$ & $\begin{array}{c}\text { CLA } \\
(n=5)\end{array}$ & SEM $^{3}$ & P-Value ${ }^{10}$ & $\begin{array}{c}\text { CON } \\
(n=4)\end{array}$ & $\begin{array}{c}\text { CLA } \\
(n=5)\end{array}$ & SEM $^{3}$ & P-Value ${ }^{10}$ \\
\hline $\begin{array}{l}\text { REA174 } \\
\left(\mathrm{cm}^{2}\right)\end{array}$ & $90.08 \mathrm{a}$ & $99.94 \mathrm{~b}$ & 4.46 & 0.04 & 91.44 & 100.98 & 4.46 & 0.07 & 98.39 & 106.91 & 4.46 & 0.07 \\
\hline $\begin{array}{l}\text { BF175 } \\
(\mathrm{cm})\end{array}$ & 0.37 & 0.45 & 0.03 & 0.3 & 0.29 & 0.34 & 0.03 & 0.54 & 0.43 & 0.46 & 0.03 & 0.7 \\
\hline $\begin{array}{l}\text { REA136 } \\
\left(\mathrm{cm}^{2}\right)\end{array}$ & 82.26 & 85.86 & 0.62 & 0.38 & 77.53 & 83.34 & 0.62 & 0.16 & 91.13 & 92.34 & 0.62 & 0.77 \\
\hline $\begin{array}{l}\text { BF137 } \\
(\mathrm{cm})\end{array}$ & 0.42 & 0.59 & 0.05 & 0.21 & 0.32 & 0.48 & 0.05 & 0.23 & 0.47 & 0.67 & 0.05 & 0.15 \\
\hline $\begin{array}{l}\text { IMF8 } \\
(\%)\end{array}$ & 3.54 & 3.73 & 0.33 & 0.56 & 3.77 & 3.65 & 0.33 & 0.72 & 3.72 & 3.69 & 0.33 & 0.92 \\
\hline $\begin{array}{l}\text { RFT9 } \\
(\mathrm{cm})\end{array}$ & 0.55 & 0.76 & 0.12 & 0.5 & 0.81 & 0.94 & 0.12 & 0.66 & 0.87 & 0.86 & 0.12 & 0.43 \\
\hline
\end{tabular}

a,b Within day, means with different superscripts differ at $\mathrm{P} \leq 0.05$.

${ }^{1}$ Conjugated linoleic acid supplement manufactured by BASF Corp. (Florham Park, NJ).

${ }^{2}$ The initial difference in REA17 on day 0 was accounted for by utilizing a covariate.

${ }^{3}$ Pooled Standard error of the treatment mean.

${ }^{4}$ Ribeye area between the 17 th and 18 th ribs in $\mathrm{cm} 2$.

${ }^{5}$ Fat content between the 17 th and 18 th ribs in $\mathrm{cm}$.

${ }^{6}$ Ribeye area between the 13 th and 14 th ribs in $\mathrm{cm} 2$.

${ }^{7}$ Fat content between the 13th and 14th ribs in $\mathrm{cm}$.

${ }^{8}$ Percent intramuscular fat.

${ }^{9}$ Rump fat thickness in $\mathrm{cm}$.

${ }^{10}$ Dietary treatments offered at $0.015 \%$ body weight daily.

Similar to the changes observed in growth performance, REA13, BF13, REA17, BF17, IMF, and RFT did not differ across treatments (Table 2). Both REA13 and BF13 increased over time (P $<0.01$ and 0.05 , respectively) but did not differ across treatments ( $\mathrm{P}=0.22$ and 0.15 , respectively). A treatment $\mathrm{x}$ day interaction was exhibited for REA17 ( $<<0.05)$. However, because REA17 in CLA supplemented horses $\left(103.69 \pm 2.36 \mathrm{~cm}^{2}\right)$ was higher than control horses $\left(91.96 \pm 2.64 \mathrm{~cm}^{2}\right)$ on day $0(\mathrm{P}=0.04)$, REA17 was reanalyzed with day 0 as a covariate for all subsequent measures to account for this initial difference (Figure 1). After accounting for the initial variance, REA17 tended to be higher in treatment horses $\left(100.98 \pm 2.62 \mathrm{~cm}^{2}\right)$ than control horses on day $42(91.44 \pm 2.99$ $\mathrm{cm}^{2}$; $\left.\mathrm{P}<0.07\right)$. Similarly, on day 84 , REA17 ( $\left.<0.07\right)$ tended to be higher in treatment horses $\left(106.91 \pm 2.30 \mathrm{~cm}^{2}\right)$ than control horses $\left(98.39 \pm 2.62 \mathrm{~cm}^{2}\right)$. Over time, BF17 tended to be different $(\mathrm{P}=0.07)$ but did not exhibit a difference across 


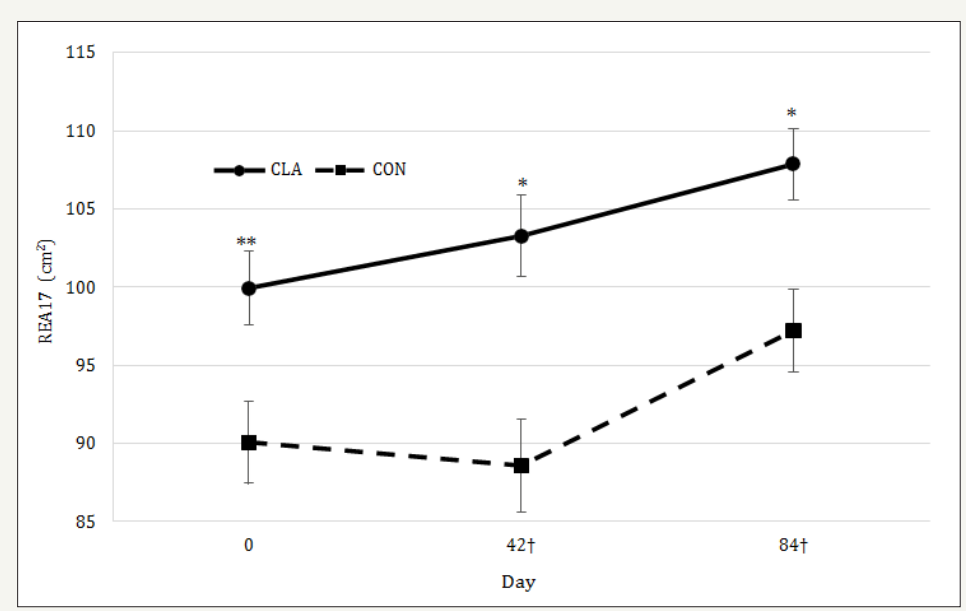

Figure 1: Changes in mean ribeye area between the $17^{\text {th }}$ and $18^{\text {th }}$ ribs $(R E A 17, \mathrm{~cm} 2)$ for horses consuming either CLA or soybean oil (CON) that served as an isocaloric control. Diets were offered at $1.5 \%$ of the total daily concentrate on an as fed basis, and top-dressed and mixed with concentrate immediately prior to feeding. A covariate was utilized to account for initial differences between treatments, as signified by $\dagger$. Within day, a double asterisk $\left(^{* *}\right)$ signifies that treatments differ at $\mathrm{P} \leq 0.05$ while a single asterisk (*) signifies a tendency for treatments to differ at $\mathrm{P}<0.07$. Pooled Standard error of the treatment mean was used as an indication of variation.

treatments $(\mathrm{P}=0.30)$. Lastly, RFT increased over time $(\mathrm{P}<0.01)$, but did not differ across treatments $(\mathrm{P}=0.51)$. Data from the current study indicates that CLA does not affect body fat content, including RFT, IMF, BF13, and BF17.

These results are in contrast with previous literature that demonstrated t10, c12- CLA supplementation alters body composition by decreasing body fat content in finishing swine $[1,9,10]$. This difference may be the result of a species-dependent effect of CLA supplementation, but results from the current study also contradict data from Headley et al. [2] that indicated a tendency for CLA to increase RFT in horses. Alternatively, if the effect of CLA is dependent upon pre-existing adiposity, then this difference may be the result of supplementing CLA to young, developing horses as opposed to mature horses with greater fat content. Further study is needed to clarity the reason for the conflicting results.

While data from this study do not indicate a difference in REA13 between treatment groups, there was a tendency for REA17 to be higher in CLA supplemented horses. These data coincide with results of previous literature demonstrating an increase in lean muscle mass because of CLA supplementation $[1,9,10]$. However, the mechanism of action controlling this increase remains unclear. An increase in lean muscle mass due to CLA supplementation contradicts a previous study that demonstrated a shift in muscle fiber type from type IIB to type I as a result of CLA supplementation, which would cause the muscle fiber to shrink in size [8]. Additionally, while several studies have shown that dietary CLA is absorbed and incorporated into circulation as early as 2 to 6-week of supplementation $[2,18]$, the incorporation into tissues inevitably takes longer and changes to the tissue require even greater length of supplementation.

The authors acknowledge a limitation to this study in that dietary and plasma fatty acid levels were not analyzed. Although this information was outside the scope of this work, the information would be beneficial to include as a means to evaluate the incorporation of CLA over time to provide a greater insight to the relative time course required for the effective incorporation across the gastrointestinal tract and into active tissue sites in order to elicit potential effects. Therefore, it is possible that a longer supplementation period will be necessary to demonstrate a difference in both fat content and lean muscle mass between control oils and CLA.

\section{Conclusion}

In summary, dietary supplementation of CLA at $0.015 \%$ BW over a 12-wk feeding period tended to increase lean muscle mass but did not affect overall morphometric measurements. Further study to determine an appropriate inclusion rate in the equine diet may clarify the effect of CLA on body composition, including fat content, particularly if supplemented to horses across various breeds and biological types in an effort to improve performance and longevity of horses.

\section{Acknowledgement}

The Department of Agricultural Sciences and Engineering Technology at Sam Houston State University provided financial support to conduct this research.

\section{Conflict of Interest}

The sponsor had no input in the study design, analysis, interpretation of data, or the decision to submit the article for publication.

\section{References}

1. Ostrowska E, Muralitharan M, Cross RF, Bauman DE, Dunshea FR (1999) Dietary conjugated linoleic acids increase lean tissue and decrease fat deposition in growing pigs. J Nutr 129(11): 2037-2042.

2. Headley S, Coverdale JA, Jenkins TC, Klein CM, Sharp JL, et al. (2012) Dietary supplementation of conjugated linoleic acid in horses increases plasma conjugated linoleic acid and decreases plasma arachidonic acid but does not alter body fat. J Anim Sci 90(13): 4876-4882. 
3. Wang T, Lee HG (2013) Advances in research on cis-9, trans-11 conjugated linoleic acid: A major functional conjugated linoleic acid isomer. Crit Rev Food Sci Nutr 55(5): 720-731.

4. Lehnen TE, da Silva MR, Camacho A, Marcadenti A, Lehnen AM (2015) A review on effects of conjugated linoleic fatty acid (CLA) upon body composition and energetic metabolism. J Int Soc Sports Nutr 12: 36

5. Belury MA (2002) Dietary conjugated linoleic acid in health: physiological effects and mechanisms of action. Annu Rev Nutr 22:505-531.

6. Pariza MW (2004) Perspective on the safety and effectiveness of conjugated linoleic acid. Am J Clin Nutr 79(6 suppl): 1132S-1136S.

7. Koba K , Yanagita T (2014) Health benefits of Conjugated Linoleic Acid (CLA). Obes Res Clin Pract 8(6): e525-e532.

8. Kim JH, Kim Y, Kim YJ, Park Y (2016) Conjugated linoleic acid: Potential health benefits as a functional food ingredient. Annu Rev Food Sci Technol 7: 221-244.

9. O'Quinn PR, Nelssen JL, Goodband RD, Unruh JA, Woodworth JC, et al. (2000) Effects of modified tall oil versus a commercial source of conjugated linoleic acid and increasing levels of modified tall oil on growth performance and carcass characteristics of growing-finishing pigs. J Anim Sci 78(9): 2359-2368.

10. Thiel-Cooper RL, Parrish FC Jr, Sparks JC, Wiegand BR, Ewan RC (2001) Conjugated linoleic acid changes swine performance and carcass composition. J Anim Sci 79(7): 1821-1828.

11. Zhang H, Dong X, Wang Z, Zhou A, Peng Q, et al. (2016) Dietary conjugated linoleic acids increase intramuscular fat deposition and decrease subcutaneous fat deposition in yellow breed x simmental cattle. Anim Sci J 87(4): 517-524.

12. Henneke DR, Potter GD, Kreider JL, Yeates B F (1983) Relationship between condition score, physical measurements and body fat percentage in mares. Equine Vet J 15(4): 371-372.

13. Carter RA, Geor RJ, Staniar WB, Cubitt TA, Harris PA (2009) Apparent adiposity assessed by standardized scoring systems and morphometric measurements in horses and ponies. Vet J 179(2): 204-210.

14. Westervelt RG, Stouffer JR, Hintz HF, Schryver HF (1976) Estimating fatness in horses and ponies. Journal of Animal Science 43(4): 781-785.

15. Perkins TL, Green RD, Miller MF (1992) Evaluation of alternative ultrasound measurement sites as estimators of yield grade factors in beef cattle. Proc Western Sect Am Soc Anim Sci 43: 294-297.

16. Chin SF, Storkson JM, Albright KJ, Cook ME, Pariza MW (1994) Conjugated linoleic acid is a growth factor for rats as shown by enhanced weight gain and improved feed efficiency. J Nutr 124(12): 2344-2349.

17. Noto A, Zahradka P, Yurkova N, Xie X, Nitschmann E, et al. (2006) Conjugated linoleic acid reduces hepatic steatosis, improves liver function, and favorably modifies lipid metabolism in obese insulinresistant rats. Lipids 41(2): 179-188.

18. King SS, AbuGhazaleh AA, Webel SK, Jones KL (2008) Circulating fatty acid profiles in response to three levels of dietary omega-3 fatty acid supplementation in horses. J Anim Sci 86(5): 1114-1123.
Creative Commons Attribution 4.0 International License

For possible submissions Click Here
Submit Article

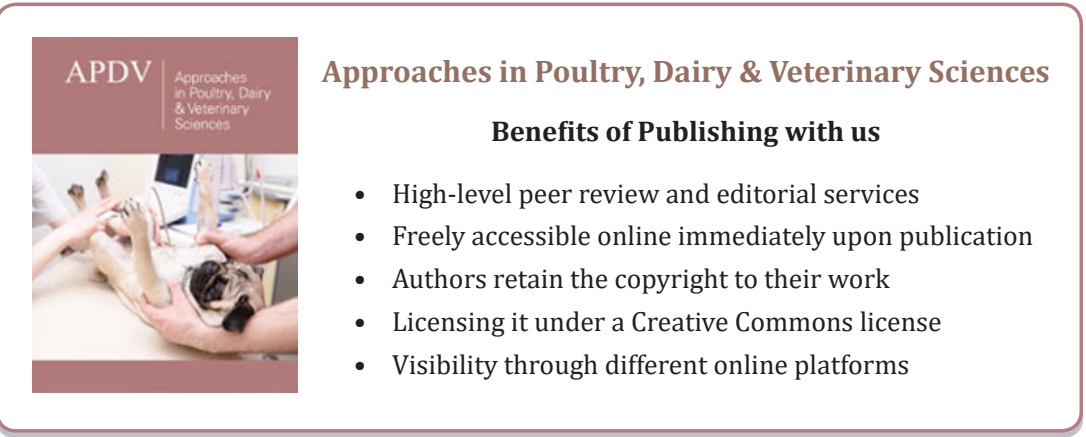

